\title{
MERCADO, PRODUCCION AGRICOLA Y CAMBIO ECONOMICO EN MALLORCA DURANTE EL SIGLO XVIII*
}

\author{
CARLES MANERA
}

Universitat de les Illes Balears

\section{PRODUCCION Y CONSUMO TRADICIONAL DE ALIMENTOS}

Uno de los elementos que caracterizan la economía mallorquina del Antiguo Régimen es la escasez productiva de cereales, presentada generalmente como un factor dramático de dependencia. La información al respecto es copiosa, pero debe interpretarse con suma precaución. Los fondos archivísticos contienen numerosos expedientes y memoriales que, remitidos al rey y a los encargados de sus rentas por los representantes municipales y de los organismos autónomos, plantean, en síntesis, un mensaje muy claro: la queja por la falta de grano, y la necesidad de controlar su producción para evitar así calamidades demográficas. Sin embargo, cabe pregun. tarse hasta qué punto esas consideraciones son siempre fieles a la realidad, o se trata más bien de apreciaciones formuladas, en algunos casos, de forma exagerada con el objetivo de permitir la extracción de mercancías vetadas y/o fiscalizadas, que se presentan entonces como seguras compensadoras de la balanza comercial. Ese argumento, asumido por los dirigentes insulares, se utilizaría, incluso, en momentos poco o nada inciertos, para presionar la liberalización mercantil o para aligerar las tasas impositivas que gravan el comercio. Recuérdese que los cereales que faltan en Mallorca se compran a cambio de aceite, aguardiente, almendras, almendrón y queso - entre otros productos-, renglones que soportan una apreciable carga fiscal, del orden mínimo del 15 por 100 de su valor ${ }^{1}$. Paralelamente, no puede relegarse la "Cuestión social" del planteamiento descrito: el temor a posibles revueltas populares, consecuencia de las carestías frumentarias.

- El presente estudio forma parte del proyecto de investigación Estructura comercial e industria precapitalista en Mallorca, patrocinado por la "Dirección General Científica y Técnica* (DGCYT), del Ministerio de Educación y Ciencia. Agradezco a Alfons Barceló, Josep María Delgado, Biel Jover, Carlos Martínez Shaw, Eva Serra y Enric Tello sus comentarios y sugerencias. Ellos no son, lógicamente, responsables de los errores que contienen las páginas que siguen.

1 C. Manera (1988a). 
Muchos de los testimonios que declaran la insuficiencia triguera en la isla delatan, paradójicamente, la positiva capacidad de las cosechas. En tal sentido, los ejemplos abundan más de lo que puede suponerse, y se vinculan tanto a la estrategia de los productores y controladores de los excedentes comercializables como a la de los funcionarios de la hacienda real, inclinados a incrementar al máximo las arcas del monarca.-En ambos casos, la situación objetiva de la economía mallorquina parece interesar poco, toda vez que se persigue un aprovechamiento puntual de la coyuntura; dicho con otras palabras: el "bien común" - tan enaltecido en la época- se convierte, ahora, en el bien particular. Y es este último el que de verdad cuenta.

A fines del siglo XVII ya existe, entre los delegados reales, una clara preocupación por los problemas de las finanzas del soberano. En Mallorca esto se traduce en un interés evidente por comercializar los diezmos de cereales correspondientes al rey, de manera que cuando las cosechas son importantes urge despachar la cuota decimal para restaurar así cen lo posible el menoscabo que se experimenta en [la] Real bazienda" ${ }^{2}$. Ahora bien, cuando la producción es insuficiente, la intención del virrey no es otra que persistir en las ventas de los citados impuestos, lo cual genera conflictos con los representantes insulares, reticentes en canalizar hacia el exterior remesas cerealícolas que son indispensables en la isla. En primer lugar, debe verse aquí una angustia, más que justificada, por el estallido de disturbios populares, propios de las crisis de subsistencias, si la escasez alcanza límites difícilmente sostenibles por las clases más humildes - se ha de preservar el "bien común" cuando puede poner en peligro el particular-. Por otro lado, se notifica la tendencia de los burócratas reales en obtener los máximos recursos para su señor, trasladando los costos sociales a los administradores locales. Esta contradicción es una especie de círculo vicioso en el cual se insertan las diferentes perspectivas e intereses de los dominadores. El Procurador Real suele presentar una tesis muy efectiva, desoyendo las recomendaciones de las entidades mallorquinas: deben extraerse los diezmos del rey durante los días previos a la cosecha de los posibles puntos de consumo, es decir, cuando la perentoriedad frumentaria es más acuciante, ya que así se garantizan mayores entradas para la corona. Estamos, pues, ante una muestra más de las ansias especulativas de la política real, por otra parte tan crítica con las prácticas agiotistas - también son frecuentes los textos en ese sentido-, que sanciona una verdad inapelable: cuando más trigo hay en el mercado, más barato es y, por consiguiente, existen menos posibilidades de beneficios ${ }^{3}$.

2 Arxiu de la Corona d'Aragó (=ACA), legajo 987. La noticia es de 1686.

3 Véanse ejemplos al respecto en la referencia citada supra. nota 2. 
El orden social inquieta notablemente. Pero las autoridades, al margen del dramatismo que imprimen a sus escritos, actúan con una racionalidad muy clara, constatable en la documentación que emiten. Porque, cuando falta trigo, las estrategias para conseguirlo se multiplican: el temor al conflicto social legitima todo tipo de actuaciones si se obtiene aquel producto básico. Los organismos oficiales también confirman la cantidad de numerario disponible para las compras de cereales, de manera que se corrobora una patente eficiencia que no debe infravalorarse. Véase cómo, por ejemplo en 1789 - caso que puede sintetizar muchos de los sistematizados-, se consignan "basta veinte mil libras por abora para emplearlas en el negocio del trigo; y si acaso fuere necessaria aun más cantidad lo propondrá al Real Acuerdo dan. do al mismo tiempo razón de lo invertidon. Se comprueba la serenidad de las afirmaciones precedentes, conscientes de la dificultad que conlleva la escasez, pero alejadas de aquellas que, formuladas principalmente para ser leídas fuera de la isla, o bien para dramatizar sobre la situación real, con razón o sin ella - pero siempre con intencionalidad política-, exhiben una situación alimenticia caótica y casi irresoluble. Este cierto aplomo se concreta, siguiendo en 1789, en la certificación "en el menor tiempo posible [de] la entrada en la Ysla [de cuatro mil] quarteras de trigo (...) Si por la situación de sircunstancias pareciese combeniente a la Ciudad bacer aun introducción de mayor partida, proceda igualmente a su verificación dando parte de todo al Real Acuerdo para que por ningún acontesimiento falte este necesario abastom. El paso determinante para poner en funcionamiento tales propósitos no es otro que conocer "quienes son los Mercaderes y tratantes en granos que bay en esta Ciudad (...) y las noticias que [se] tengan acerca de las cantidades de trigo que existan en poder de dichos tratantes ${ }^{4}$. El avituallamiento pasa, pues, por la actitud que adopten los comerciantes, hecho que no satisface a los ediles, mayoritariamente nobles, quienes matizan las recomendaciones de otras instituciones -como el Real Acuerdo- en relación a las formas de las provisiones frumentarias. Sin embargo, los regidores se mueven en una clara ambigüedad, dado que dependen de las gestiones de los cargadores para introducir trigo en Mallorca, al tiempo que se aperciben del poder que significa esta especie de monopolio.

Pero el tema de los alimentos no se concentra tan sólo en los cereales: se impone, también, contemplar otros productos que, como las legumbres,

4 Arxiu del Regne de Mallorca (=ARM), «Diputació" (=D), núm. 569. Se aconseja que los cerèales se adquieran principalmente en Marsella, Génova, Cerdeña, Sicilia, Africa y el litoral español, "donde pareciera baver mayor proporción para que cuanto antes se verifique la introducción de granosi. Acudir a los comerciantes es la solución principal que adoptan las autoridades ante el peligro de escasez frumentaria. Véanse ejemplos al respecto en Arxiu Municipal de Palma (=AMP), «Resolucions de l'Ajuntament” (=RA), 1766, tomo II, fol. 27v; AMP, RA, 1773, fol. 127v. Igual sucede con los suministros cárnicos; cfr. E. Bejarano (1989). 
son determinantes para el sustento de la población. En tal aspecto, unos sencillos cálculos sirven para situar mejor este punto. Se han determinado los coeficientes de correlación entre todas las producciones cerealícolas y las leguminosas para el período 1717-1819 (véase cuadro 2), dividiéndolo en tres fases concretas en función de las crisis demográficas (1717-1752, 1753-1785 y 1786-1819), obteniéndose los resultados que paso a comentar. La primera fase patentiza una alta correlación entre todos los cereales: el trigo marca la pauta productiva y arrastra al resto de los granos; idéntica conclusión cabe adoptar en relación a las legumbres. Así, pues, éstas no son un componente sustitutivo del principal cereal en estos años, sino un producto que actúa cada vez más - desde la segunda mitad del Seiscientos 5 como un efectivo complemento de la dieta alimenticia. Los datos del segundo período constatan la importante correlación entre cereales y legumbres. Las cosechas trigueras parecen funcionar con una lógica más vinculada a las leguminosas que a la cebada y la avena; dicho de otra forma: las legumbres pueden desplazar a los cereales menores. La última etapa describe una significativa correlación entre estos últimos y entre legumbres y avena. Igualmente, se observa un claro descenso entre cebada/avena y trigo, mientras se certifica una situación similar entre éste y las legumbres. Es decir, se sugiere que el cereal más importante dispone de productos - cebada, leguminosas - que no únicamente son complementarios en la alimentación de las clases más humildes, sino que también pueden suplantarlo en épocas de escasez y/o fluctuaciones bruscas, al alza, de los precios frumentarios. Además, cabe tener en cuenta:

1. La caída de las cotas productivas de los cereales, con medias que denotan una tendencia a la baja, si bien en la última fase se certifica el aumento de las cosechas de cebada y avena. Las legumbres presentan un incremento productivo, con un trend evidente al alza. Son precisamente las cifras correspondientes a las legumbres las que permiten sostener un ligero aumento de la producción total de alimentos básicos en Mallorca. Esas magnitudes globales aseveran que la isla no padece una contracción general en su producción, sino una recesión de ciertos géneros en beneficio de otros.

2. Si se incorporan a las variables sobre producción las disponibles sobre importaciones de cereales y las de sus precios en el mercado de Pal$\mathrm{ma}$, se aprecia lo siguiente (teniendo presentes estos coeficientes de correlación para el período 1775-1819: precios/producción, -0,3; precios importaciones, 0,$4 ;$ producción/importaciones, $-0,2)$ :

5 Según indican las investigaciones, todavia inéditas, de Biel Jover. 
- los precios dependen limitadamente de la producción local;

- las importaciones están poco subordinadas a las variaciones de la producción;

- la relación entre movimiento de precios e importaciones es más firme.

Es decir, el principal mercado urbano mallorquín se vuelca decididamente hacia el mar para cubrir sus déficits alimenticios, lo que no quiere decir que deje de consumir las remesas cerealícolas que proceden de la zona rural de la isla. Se podría aventurar que, más que Mallorca en general, el núcleo que siempre necesita trigo es Palma, de forma que se confirma la estrecha conexión de la isla con los mercados avitualladores de granos. Esto, al tiempo que invalida - una vez más - el mito de la insularidad, patentiza una de las subliminales intenciones que abrigan las quejas de las autoridades: su interés en aportar trigo forastero, más barato en comparación con el valor que alcanza en el mercado interior. En tal aspecto, los datos del cuadro 1, establecidos a partir de los libros contables de los comerciantes Blai Billon y Antoni y Claudi Marcel, firmas muy reconocidas en la segunda mitad del Setecientos mallorquín, son bien ilustrativos: los precios del grano en el exterior (Alicante, Ibiza, Barcelona, Cartagena, Lorca, Marsella, Mahón, en los ejemplos consignados) son más ajustados que los alcanzados en el mercado de Palma. Ello constituye un diferencial interesante para negociantes y administradores locales; la incentivación de las importaciones de granos, derivadas de cifras similares a las presentadas, permiten entrever el efecto "regulador" del trigo foráneo, resumido en el descenso de los precios en el mercado urbano.

Las compras exteriores de cereales facilitan la extensión de otros cultivos, habida cuenta que la subsistencia tradicional está relativamente asegurada por la suma de la producción propia y las introducciones trigueras. Esa reorientación de la producción, localizada al menos en comarcas concretas de Mallorca, es el tema que, como referente claro del cambio económico, interesa abordar seguidamente.

\section{PRODUCCION Y ASIGNACION DE RECURSOS}

La cuestión de la asignación de recursos constituye un factor determinante que permite situar mejor los cambios acaecidos en la Mallorca setecentista, sugeridos en el apartado anterior. Se impone partir de una premisa inicial: si los recursos productivos y los conocimientos técnicos disponibles en una economía se consideran ya efectivos, esas limitaciones 
conducirán a una reducción en la producción de un bien cuando se incrementa la de otro. Es decir, cuanto más se produzca de un género determinado, menos recursos quedarán para obtener otro, de manera que su producción se ha de limitar. El coste de oportunidad de los recursos necesarios para producir una unidad de la mercancía que está expandiéndose, medida por el decrecimiento que se crea en la producción del género que se contrae, es cada vez mayor. Puede afirmarse, pues, que la producción de un bien se está convirtiendo en la del otró.

Según esto, las variables sistematizadas indican que, aproximadamente desde 1775, se consolida en Mallorca una reasignación de recursos que explica la caída de las producciones de cereales y de aceite 7 , y el crecimiento de otros renglones de la economía isleña. Ello se revela, como se ha visto, en el incremento de la producción de legumbres - que contrasta con la disminución de la cerealícola-, la significación de las hortalizas, sobre todo en ciertas zonas de la isla, y el peso cada vez más importante de la viña. Estos cultivos obedecen a una política que se justifica tanto en el autoconsumo como en el mercado.

Por un lado, la dieta alimenticia se hace menos dependiente del principal grano, el trigo: las legumbres forman parte de la nutrición cotidiana de las clases populares, al tiempo que el arroz se integra, paulatinamente, en las comidas. En este aspecto, véanse las importaciones del citado producto en el cuadro 4: las cifras son significativas entre 1779 y 1807 , aunque no guardan correlación con los años de malas cosechas cerealícolas, de forma que cabe suponer que las compras de arroz funcionan con una dinámica más independiente de las perentoriedades de los consumidores. Las capas populares consumen una dieta compuesta por diferentes ingredientes, combinados de manera monótona: pan - de trigo y cebada -, aceitunas, arroz, legumbres, higos, pescado salado, algo de queso y de hortalizas y pequeñas raciones de carne de cabra; el agua y el aguardiente constituyen las bebidas más frecuentes. Entre las legumbres y las hortalizas, interesa resaltar que lentejas, garbanzos, guijas, ajos, tomates, coles y, sobre todo, habas significan elementos cruciales de la dieta popular; lo mismo puede afirmarse en relación a la cebada, cuya producción tiende ligeramente al alza, contrastando con la del trigo, claramente en declive. Estamos, por tanto, ante alimentos de carácter alternativo cuando el pan se convierte en una mercancía poco accesible, dados sus altos precios de venta. Este tipo de comida, nada extraña entre el campesinado insular cuando falta el trigo, puede ayudar a comprender mejor la relativa resistencia a las enfermedades de dicha clase

\footnotetext{
- Como marco teórico, cfr. R. Findlay (1975: 25-35); J. Segura (1984: 16-33)

T Para el aceite, véanse G. Davíu (1983: 391-410) y J. Juan (1980: 519-552). Para los cereales, I. Moll y J. Suau (1985: 275).
} 
social y, en suma, algunos de los indicadores demográficos disponibles ${ }^{8}$. No puede ignorarse que el nivel proteínico de la dieta que contiene legumbres en proporciones significativas es mayor que la basada en cereales panificables, si bien su peso en hidratos de carbono es inferior. Si se toman como sustento diario para los grupos sociales más desfavorecidos unos 485 gramos de pan, 200 de habas, 0,35 litros de vino, 0,026 litros de aceite y unos 36 gramos de queso, prescindiendo del pescado y la carne, y con una cuota muy baja en leguminosas - como queda patente-, las kilocalorías que sintetizan tales ingredientes suman alrededor de las $2.000^{9}$, Piénsese que tal composición se ciñe a aquellos momentos en los que el pan puede adquirirse a precios razonables, de manera que en coyunturas problemáticas - malas cosechas trigueras, alza de los precios- sería sustituido por una mayor cantidad de, por ejemplo, habas, lentejas y verduras. El carácter más proténico de esa dieta es notorio, aunque el pan sea entonces un bien escaso.

Por otra parte, los géneros vitícolas facilitan una mayor integración en los circuitos mercantiles, tanto en los interiores como en los exteriores. En Mallorca, el consumo de aguardiente se caracteriza por su importancia y regularidad, y se convierte en una de las bases calóricas más significativas de la alimentación popular. Pero, además, dicho licor facilita una mayor permeabilidad de la economía campesina en relación al capital comercial, que reclama cantidades de un producto estimado sobre todo en los mercados norteatlánticos. La producción de vinos destilados suele realizarse en pequeña escala, bajo mecanismos que, en muchas ocasiones, recuerdan los estimulados con la manufactura textil (putting-out, kaufsystem). Así, el pequeño productor, que cuenta en su casa con un elemento tan simple y barato como es el alambique, dispone, fabricando porciones reducidas de licor, de modestas remesas de dinero que, sin embargo, son determinantes para adquirir otras mercancías o pagar los impuestos ${ }^{10}$. Al mismo tiempo, cabe considerar las producciones de hortalizas y leguminosas como piezas

* Sobre la cuestión de la alimentación en Mallorca, consúltense especialmente los recientes trabajos de O. Vaquer (1985; 1988: II, 739-766), J. Roselló (1985), A. Quintana (1985) y J. F. López Bonet (1986). Desde una perspectiva más general, cfr. V. Pérez Moreda (1985). En relación a los datos demográficos de la isla, véanse I. Moll, A. Segura y J. Suau (1983) y A. Segura y J. Suau (1984).

${ }_{9}$ Esta base alimenticia - citada por O. Vaquer (1988: II, 743-745) - se refiere al siglo XVI, lo cual relativiza los datos expuestos. Cabe precisar que un gramo de pan contiene 7,8 proteínas, mientras uno de habas representa 15,33 . Sin embargo, los hidratos de carbono manifiestan una tendencia inversa: en un gramo de pan hay unos 38 , mientras en igual cantidad de habas existen 29. Los resultados comentados se han obtenido a partir de las tablas de alimentos de M. M. Andújar, O. Molina y F. Gil (1987), aplicando los coeficientes que exponen estos investigadores.

11. C. Manera (1988c). 
claves de la estrategia campesina, toda vez que, siendo parte decisiva de una alimentación que puede relevar a los cereales tradicionales, sirven también para participar en los flujos comerciales internos ${ }^{11}$.

Las coyunturas de fuertes crisis permiten comprobar algunos de los cambios generados en la economía mallorquina, con sus manifestaciones ya apuntadas. Este es el caso del difícil período que engloba los años 17441750 - sin duda el más negativo de la centuria-, con claros exponentes en el importante descenso de las cosechas frumentarias desde 1747 y en la recesión comercial de 1750 . El primer aspecto citado es de tal magnitud que el rey se digna a conceder la rebaja del 5 por 100 de los derechos de la aduana para aquellos géneros destinados a ser intercambiados por trigo ${ }^{12}$. Al mismo tiempo, testimonios más arraigados en la cultura popular ${ }^{13}$ indican que, en tales momentos dramáticos, los isleños se alimentaron de legumbres, arroz, algarrobas y habas, que aparecen combinados con las escasas partidas de trigo existentes. El comercio palia relativamente este déficit de alimentos: en 1749, el año culminante de la crisis, se importan 229.132 cuarteras de trigo y 60.698 de cebada, al igual que 10.526 de leguminosas y 838 quintales de harina. Los funcionarios precisan que el coste de esas remesas representa más de un millón de libras mallorquinas, más de 13 millones de reales de vellón, cantidad nada exagerada a juzgar por los cálculos establecidos a partir de los materiales de la aduana del puerto de Palma, recogidos en el cuadro $10^{14}$.

Sin embargo, los representantes de las instituciones insulares abundan en unos comentarios que extienden dicho período más allá de su estricto marco temporal; la pretensión no es otra que incidir para una reducción de la presión fiscal. En los años 1753 y 1754, las críticas a las tasas impositivas son rotundas y se personalizan, sobre todo, en la figura del Intendente General, considerado como el más fiel administrador de la política económica real. Ahora bien, la reconstrucción de los valores comerciales revela una patente recuperación del movimiento mercantil desde 1751 hasta 1760 , con cotas destacadas, precisamente, en los años 1752, 1753 y 1754 (consúltese el cuadro 8); paradójicamente, este último significa el mejor en relación al tráfico portuario durante el período 1740-1780. Lo cual nos sitúa, una vez más, en la mitificación oficial de la escasez. Por otra parte, textos que pueden calificarse como más neutrales en cuanto a la economía mallorquina permiten intuir las modificaciones que se advierten en la estructura económica de la isla desde la segunda mitad del Setecientos. En 1755, el 1988)

11 Un planteamiento similar, en Ll. Ferrer (1987), E. Serra (1988) y J. Thirsk (1984.

12 ARM, D, núm. 569.

13 Se trata de los versos del glosador Tià de Sa Real, que narra esos años críticos.

14 Supra. nota 12 
cónsul de Francia en Baleares informa a su Ministro de Marina sobre la situación de las islas. En relación a Mallorca, sus palabras son meridianas:

"l'ile [es] fertile en plusieurs fruits et danrées et les babittans mediocrement laborieux (...) Ces fruits et danrées consistent principalment en buile d'olive, amandes douces, fromage, capres au vinaigre, vin et eaude-vie, els y tienent plusieurs fabriques en laine, fil, coutton et soye dont ils font melange pour des esttofes asses grossieres qui servent en premier lieu pour leur usage, et ont en mesme tems du debit et consumacion dans le continent d'Espagne, Islas de Canarie, Sardaigne, Malte et Italie, comme sont des flassades ou couvertures de lit, bonets, estamines, cordellats, vayetes, bours et calamandres, tout de diverces couleurs, et dont les matteriaux sont presque tous $d u$ crù de l'ile a leception du coutton filé de Malte et partie de lin de creme (...) de Gennes (...)").

"l'isle de Mayorque est encore abondante en Grains surtout des legumes (...) des legumes ont en permet la sortie sans pourtant autre destin que le continent d'Espaigne et point du tout pour l'estranger, de sorte que les battiments de pavillon estranger ne peuvent en cbarger qu'en donant cuation quils ne le debarqueront ailbeurs qu'en Espaigne, ont envoye ces legumes principalment des fêves, en Cattalogne" 15 .

Los datos correspondientes a los diezmos reales de cereales y leguminosas confirman lo expuesto. Se advierte la irregularidad de los primeros y una cierta homogeneidad - con crecimiento sostenido- de las variables correspondientes a las habas, que aumentan gradualmente de manera que superan, desde 1780, al candeal (véase cuadro 7). Si bien estas magnitudes presentan evidentes contradicciones - las cuotas decimales trigueras, en

15 "La isla [es] fértil en muchos frutos y géneros y los habitantes [son] mediocremente laboriosos (...) Esos frutos y géneros consisten principalmente en aceite de oliva, almendras dulces, queso, alcapamas en vinagre, vino y aguardiente; tienen mucbas fábricas de lana, bilo, algodón y seda que mezclan para [elaborar] tejidos bastante bastos que sirven en primer lugar para su propio uso, y al mismo tiempo para su venta y consumo en el continente de España, Islas Canarias, Cerdeña. Malta e Italia. como son mantas, gorros, estamenas, cordellates, bayetas (...) y calamandrias, de diferentes colores, $y$ cuyos materiales son casi todos de cosecha de la isla, con la excepción del algodón hilado de Malta y parte del lino (...) de Génova." "La isla de Mallorca es abundante en Granos sobretodo legumbres (...) Se permite la salida de las legumbres sin otro destino, sin embargo, que el continente de España y en absoluto para el extranjero, de forma que las embarcaciones de pabellón extranjero no pueden cargar más que garantizando que no las desembarcarán en otro lugar que no sea España. Se envian esas legumbres, principalmente habas, a Cataluña." Archives Nationaux de Paris (=ANP), AE/B/111/342. Agradezco a Eloy Martín Corrales esta referencia. En relación a la información que se presenta, debe constatarse que en 1720 las habas constituyen el 1,74 por 100 de las exportaciones, y en 1754 este porcentaje se eleva al 4,7 por 100 . Véase C. Manera (1988a: 132, 137). 
alza, no parecen cuadrar con los índices de la producción, claramente a la baja-, lo que se confirma es el fuerte incremento de las habas (igual sucede con la cebada y, en menor medida, con las guijas): compruébese que multiplican por catorce su producción - si, efecrivamente, tomásemos estos diezmos como un valor indicativo en la misma- entre 1765 y 1795. Un elemento clave legitima esa propensión: el alto precio de las legumbres en general, que alcanzan - como sucede en el caso de los garbanzos- valores harto elevados en comparación con los cereales panificables. En tal aspecto, los cuadros 5 y 6 son convincentes, aunque representen una muestra de los primeros años del Ochocientos.

En primer término, nótese que los precios de las habas en zonas productoras son más elevados en relación a los cereales menores; es decir, con menos cantidad de la citada legumbre los réditos son mayores, y algo inferiores a los obtenidos con el trigo. Ello justificaría una política productiva que otorgaría a determinados efectos - habas, garbanzos - una situación más favorable en detrimento, sobre todo, del trigo. Recuérdese que la cebada, como las legumbres, se convierte en mercancía sustitutiva del principal grano, de manera que es este último el que padece una contracción más acusada en su producción. Es previsible que las zonas que se especializan en el cultivo de leguminosas dispongan de una mayor diversificación económica. A la vez, esa elección puede contribuir a mejorar el nivel de renta de sus habitantes, habida cuenta que significa un proceso de introducción de nuevas pautas y concepciones agrícolas que ayudan a bonificar la productividad del suelo, puesto que la legumbre nitrogena la tierra, abonándola.

Por otro lado, se observa la regularidad en las ventas de granos, legumbres, vino y hortalizas, mientras que el aceite resume las cifras más bruscas. Importa resaltar que los totales del quinquenio (1803-1807) revelan los valores superiores del vino respecto al aceite, $y$ las cifras destacadas de las hortalizas. Tampoco puede obviarse que el capítulo de granos incluye partidas de legumbres que no aparecen desglosadas, pero que, aunque a un nivel puramente cualitativo - dada la imposibilidad de cuantificarlas-, cabe tener presentes. Tales variables certifican la diversificación de la producción y la especialización de la agricultura en algunas villas de la isla. Al mismo tiempo, esto nos plantea la perspectiva de un mercado interior más articulado de lo que podía pensarse, como consecuencia de corrientes comerciales fluidas. Todo ello impone destacar lo siguiente:

1. A lo largo del Setecientos, pero sobre todo a partir del último tercio, las comarcas de Mallorca se acostumbran a producir para vender, de manera que se clarifica un proceso, lento si se quiere, pero evidente, de 
especialización agrícola y manufacturera en comarcas concretas. Por consiguiente, no estamos ante una economía caracterizada por un autoconsumo absoluto, en el cual cada villa permanece cerrada en sí misma, sin conexiones con el resto de la población. La propia existencia de tales especializaciones matiza la idea de una formación social inmóvil, desmembrada en pequeñas unidades de producción aisladas entre sí, desconocedora de las fluctuaciones del mercado, condenada tan sólo a aportar unos géneros -aceite, trigo- que, al fin y al cabo, son la causa primordial de sus penurias, dadas las relaciones de producción que suponen.

2. Las hortalizas, las legumbres y los vinos, sean destilados o no, componen, junto a otros géneros poco citados como las algarrobas, los cítricos y las almendras, mercancías que alcanzan una notable relevancia a lo largo del siglo XVIII. Son producciones que obedecen a las necesidades de consumo de las capas urbanas - caso de las hortalizas - y rurales - como las legumbres y las algarrobas-, y que obviamente se justifican en las demandas de los mercados interno y externo. Se trata de géneros que, en general, no están tan controlados por los sectores privilegiados, habida cuenta que en su negociación intervienen diferentes colectivos sociales. La pequeña propiedad, las rotaciones de cultivos, la utilización de técnicas tradicionales, deben caracterizar esa estrategia que destina menos recursos a los renglones tradicionales, y más a aquellos cuya valoración crece en los mercados.

3. Se constata un grado importante de integración del mercado interior. En tal sentido y desde una óptica global, se puede dividir Mallorca en unas áreas diferenciadas que aproximan a la compleja realidad del mercado isleño:

- La Serra de Tramuntana, abocada a producir, en régimen de quasi monocultivo -y exceptuando casos específicos como son los de Sóller y Pollença, con economías más diversificadas-, la principal mercancía de exportación, el aceite. Es una franja que no produce trigo a gran escala, ni tampoco otros géneros necesarios para su subsistencia - manufacturas, aguardientes-, de manera que los adquiere en otras comarcas a cambio de sus excedentes oleícolas.

- Las villas productoras de alimentos básicos, cereales y legumbres, con Palma, Artá, Campos, Felanitx, Lluchmajor, Manacor, Petra, Puigpunyent, Sa Pobla, Santa Margalida y Sineu como centros más destacables. Se certifica que, a fines del XVIII, las leguminosas se producen en cantidades importantes en Campos y Felanitx, poblaciones más vinculadas a la producción de vinos. 
- La zona viticola, integrada por Felanitx, Campos, Lluchmajor, Porreres, Manacor y Sencelles, que monopoliza las producciones de vino y aguardiente, al tiempo que cuenta con el mayor número de alambiques de la isla. Los recursos económicos de estos pueblos son relativamente variados, ya que existe una mayor heterogeneidad productiva y profesional. Paralela. mente, se conocen casos concretos - como el de Felanitx - de decidida asignación de los recursos disponibles hacia la viticultura, generándose subproducciones de otros capítulos - ello se aprecia en las primeras décadas del XIX en relación a los cereales, que pierden terreno por la extensión de la viña-. Así, los productos derivados de esa especialización - los aguardientes, sobre todo- se traducen en una efectiva moneda de cambio para conseguir los géneros que urgen en la localidad ${ }^{16}$.

- El área más húmeda, hortícola y productora de materias primas, formada por Sa Pobla, Muro, Palma/Marratxí, Alcúdia, Artá, Manacor y Sineu. Las mayores disponibilidades acuíferas y la existencia de economías más complejas, con mayores alternativas, pueden explicar la dedicación, bastante especializada, hacia unas producciones - cebollas, ajos, tomates, judías - destinadas a las demandas comarcal y a la del principal mercado urbano, Palma. Por otra parte, debe recordarse que la presencia del agua también promueve en Sa Pobla y Muro la producción de unos inputs, el lino y el cáñamo, que nutren, junto a las importaciones de tales materias primas, la infraestructura manufacturera de otras villas ${ }^{17}$.

- La zona manufacturera, en la cual se insertan sobre todo -aparte de Palma- Artá, Felanitx, Llucmajor, Manacor, Porreres, Pollença e Inca, que agrupan la mayoría de los telares, de lana y lino, existentes en la zona rural de la isla.

Nótese que, grosso modo, parece existir una división del trabajo bastante clara. La montaña proporciona el aceite, es decir, el grueso de las exportaciones y un condimento elemental para la dieta alimenticia; la zona central de la isla cultiva el sustento básico, el trigo; mientras el área del levante aporta unas mercancías, materias primas textiles, vinos, aguardientes y hortalizas, que surgen de una nueva especialización agrícola a causa de la reasignación de los recursos. Lo que se pretende enfatizar es que esas especializaciones (ya sea la oleícola, la triguera, la vitícola o la hortícola) generan unos flujos comerciales internos que los historiadores no han considerado en la medida precisa, tal vez porque, como afirma J. Fontana ${ }^{18}$, no

16 C. Mancra (1988a).

17 M. Deyà (1988); C. Manera (1988b)

$18 \mathrm{~J}$. Fontana (1986). 
son, esos tráficos de alcance modesto, tan vistosos y espectaculares como las expediciones marítimas. Piénsese, además, que el mercado mallorquín dispone de un factor que facilita su cohesión: el comercio de cabotaje local, perfectamente documentado, que enlaza los diferentes puertos del litoral insular con sus respectivos binterlands. Aparte del de Palma, los puertos de Alcúdia, Sóller, Felanitx y Andraitx, que funcionan con intermitencias a lo largo de la centuria - para señalar tan sólo los más conocidos-, dinamizan el comercio interior al margen del transporte terrestre y agilizan tanto los intercambios intercomarcales como los exteriores.

\section{EL COMERCIO EXTERIOR}

Hasta ahora se han analizado los factores más internos de la economía mallorquina, si bien se han apreciado claras vinculaciones con el ámbito de la circulación. Es importante incorporar a esas reflexiones los nuevos indicadores establecidos para el comercio, toda vez que su estudio contribuye a explicar las variaciones del aparato productivo insular.

Los intercambios mallorquines se fundamentan en las exportaciones de productos agrarios (aceite, básicamente), manufacturas textiles (gorros y mantas de lana, lienzos de lino) y las mercancías derivadas de la viticultura (vinos y aguardiantes). La isla importa esencialmente cereales (trigo y cebada), telas de calidad (de seda y algodón), coloniales (azúcar, cacao) y las materias necesarias (lino, algodón, hierro, cueros, pieles) para el funcionamiento interno de la infraestructura manufacturera. El aceite integra, aproximadamente, entre el 70 y el 80 por 100 de los valores de las exportaciones, mientras los cereales constituyen porcentajes que oscilan entre el 65 y el 90 por 100 de las importaciones; las variables que se aportan en el cuadro 8 representan una estimación del cómputo global de ambas, referidas al puerto de Palma. Debe apreciarse que estas valoraciones son a la baja: la aduana sigue aplicando el arancel de 1734, que concede una tasa de 13 reales de vellón por cada arroba de aceite extraída; al mismo tiempo, se omiten las cifras sobre entradas frumentarias, dados los ajustados guarismos de las importaciones. Nótese cómo, en el caso del aceite, los precios mínimos alcanzan valores más elevados que los que se detallan: en 1782, por ejemplo, ese avalúo se concreta en 27 reales de vellón por arroba. Tal situación no es desconocida para Romualdo de Tovar, Subdelegado de Rentas en Mallorca a fines del Setecientos, preocupado en acrecentar las arcas reales. Este alto funcionario afirma que la diferencia - de 14 reales de vellón por arroba - "minora el valor del 15 por 100 (...) y por esta regla todos los demás frutos". De nuevo se aprecia el interés por incrementar los réditos de 
la Monarquía mediante una mayor presión fiscal, lo cual, al mismo tiempo, tiende a favorecer la dinamización del mecanismo más genuino para enfrentarla: el contrabando. Así, abogar por un cambio arancelario -pues "aumentaría el Rey su renta en este solo ramo del Aceite de 200 a 250 mil reales todos los años" - no hace sino incentivar las distintas estrategias que sustentan el tráfico delictivo de mercancías ${ }^{19}$. No es posible, por el momento, aproximar la proporción existente entre el comercio legal y el ilegal para el caso de Mallorca ${ }^{20}$, de manera que el análisis mercantil descansa siempre sobre los datos de carácter "convencional" obtenidos -excluyendo el corsarismo, dado que esta modalidad comercial requiere un tratamiento específico.

De los valores del comercio legal desde la segunda mitad del Xvill se desprende:

1. El cálculo de las relaciones reales de intercambio. Los indicadores del cuadro 10 parecen claros: el valor del trigo, por unidad física, es supe. rior al del aceite. Ahora bien, esto no es sinónimo de que las relaciones reales de intercambio sean constantemente desfavorables para Mallorca. El cómputo que se ha efectuado, aplicando números índices simples - habida cuenta que se ha trabajado sobre dos mercancías, aceite y trigo, es decir, cerca del 80 por 100 del comercio-, demuestra estos resultados:

\begin{tabular}{|c|c|c|c|}
\hline & $\begin{array}{l}\text { Indice precio } \\
\text { del aceite }\end{array}$ & $\begin{array}{l}\text { Indice precio } \\
\text { del trigo }\end{array}$ & $\begin{array}{l}\text { Relacion real } \\
\text { de intercambio }\end{array}$ \\
\hline 1792 & 100 & 100 & 100 \\
\hline 1793 & 135,89 & 119,16 & 114 \\
\hline 1794 & 122,34 & 117,63 & 104 \\
\hline 1795 & 123,15 & 130,80 & 94 \\
\hline 1796 & 143,63 & 130,16 & 110 \\
\hline 1797 & 166,72 & 124,90 & 133 \\
\hline 1798 & 154,51 & 104,94 & 147 \\
\hline 1799 & 142,64 & 162,90 & 88 \\
\hline 1800 & 128,04 & 149,40 & 86 \\
\hline 1801 & 129,84 & 118,60 & 109 \\
\hline 1802 & 135,02 & 128,38 & 105 \\
\hline 1803 & 117,98 & 132,74 & 89 \\
\hline 1804 & 142,70 & 146 & 98 \\
\hline
\end{tabular}

19 Archivo General de Simancas (=AGS), "Dirección General de Rentas, 2." remesa" (=DGR $2{ }^{2}$ ), legajo 1.056 .

20 El tráfico de contrabando está siendo objeto de estudio por parte de Andreu Bibilo. ni, quien ha ofrecido ya unos primeros resultados al respecto (1988). 
Véase que dichas relaciones se mantienen en unos márgenes de cierta regularidad, con dos años, 1797 y 1798, claramente positivos para las exportaciones oléicolas en función de las introducciones trigueras.

2. La estimación del comercio legal impone matizar, principalmente, las cifras referentes a las exportaciones ${ }^{21}$. Estas, como ya se ha indicado, están totalizadas a la baja: se refieren a precios arancelarios y no a los de los mercados exteriores. Cabe recordar, en tal aspecto, que los propios administradores señalan que el valor del aceite en Mallorca es superior al fijado para tasar el que se carga para la exportación. A pesar de ello, los cuadros 8, 9 y 10 permiten intuir el ritmo del comercio exterior del puerto de Palma a lo largo de casi setenta años. Los datos del primero de ellos se han suavizado con medias móviles de cinco años, manifestándose una tendencia irregular marcada por las fases que a continuación se describen:

a) 1744-1748: bajada de las exportaciones debido a la crisis de 17441750, que, en las variables absolutas, se expresa de manera abrupta por el fuerte descenso de 1750. Las malas cosechas contribuyen a esa recesión extractiva, mientras las importaciones señalan una regularidad a la baja.

b) 1749-1759: recuperación de las exportaciones, correlacionada con las cifras de las importaciones. El crecimiento del comercio es evidente en estos años, lo cual sugiere un impulso de la producción oleícola. No obstante, se indica un claro retroceso durante el bienio 1756-1758, preludio del importante descenso de 1759. Es precisamente a partir de ese año cuando se advierte el retroceso productivo del aceite, con índices que van del 87,54 para el decenio 1760-1769 hasta el 49,78 para el 1800-180922.

c) 1760-1768: ligero avance exportador, relacionado previsiblemente con otras mercancías al margen del aceite - quesos, almendrón, manufacturas y productos vitícolas-, a juzgar por los datos de la balanza de $1768^{23}$, si bien aquel renglón sigue constituyendo la pieza determinante en la estructura del tráfico.

d) 1769-1778: caída de las exportaciones entre 1769 y 1771, para dar

21 Pienso que éstas son fiables. He comparado algunas de las variables del cuadro 8 - las susceptibles de contrastación hasta el momento: las exportaciones de 1754 y 1768 -, concretadas a partir de los materiales de Simancas, con las establecidas con los libros de la aduana del puerto de Palma. Los resultados son como siguen. Para 1754, según la aduana, el valor de las exportaciones es 5.354 .000 reales de vellón, mientras la cantidad que of rece la Dirección General de Rentas es de 5.394.367; la diferencia es mínima. Para 1768, los cálculos efectuados sobre la contabilidad aduanera son de 2.248 .004 reales de vellón, y los que consigna la Dirección General de Rentas se elevan a 2.249.407; el margen sigue siendo irrisorio. Véase un análisis general de los impuestos aduaneros en T. García Cuenca (1983).

22 Cfr. G. Davíu (1983: 407-408)

23 C. Manera (1987: II, 37-46). 
paso a una esporádica recuperación en 1772 que se reinicia dos años después hasta 1778. A partir de este año se dispone tan sólo de cálculos sobre el movimiento importador (cuadro 9).

Si se prescinde de las entradas frumentarias pãra el periodo 1744-1778, debe señalarse que las importaciones se caracterizan por la regularidad, con dos fases claves de crecimiento (1750-1756 y 1761-1765), que coinciden con momentos expansivos de las exportaciones. Desde 1778, el período más destacable es el que abraza los años 1795-1808, que, además, permite integrar cálculos de la práctica totalidad de los registros de las balanzas comerciales (con una aproximación de un 80 por 100; véase cuadro 10). Se trata de una coyuntura que se salda con reducidos superávits en algunos años $(1795,1797,1798,1801,1802,1803)$, fuertemente contrarrestados por déficits draconianos. Sin embargo, esos datos ponen en relieve que no se dan desequilibrios crónicos en la balanza comercial, si bien cuando éstos se producen son de considerable envergadura, subsanables, posiblemente, por las remesas de capitales provenientes del exterior y por determinadas partidas invisibles - cambios y seguros maritimos, principalmente-. Así pueden explicarse los resultados, claramente negativos, de los años 1799-1800 y, sobre todo, de 1804-1806, en unos momentos aparentemente dificultosos -de crisis agrícola y de descenso de las exportaciones oleícolas-, pero insertos en las coordenadas cronológicas que sancionan la consolidación de una "segunda generación" de comerciantes y conocen, al mismo tiempo, la integración efectiva de Mallorca en el mercado mundial ${ }^{24}$.

Se han podido determinar algunas de las transferencias de capital hacia la isla en años concretos y desde diferentes puntos (véase cuadro 11), apuntándose, con muchas precauciones, hipótesis sobre los mecanismos reguladores del comercio. Dos aspectos llaman la atención de las cifras presentadas. Por un lado, el importante volumen de dinero remitido, que tal vez facilita resultados positivos en la balanza de pagos. Dos ejemplos sirven para corroborar lo afirmado. En 1787, el valor de las exportaciones es de unos 2,2 millones de reales de vellón, mientras las importaciones representan más o menos dos millones. Compruébese que la cantidad ingresada en moneda es similar a la de las valoraciones aduaneras de mercancías; por consiguiente, el saldo de la balanza de pagos de ese año - teniendo en cuenta tan sólo dichas partidas- se situaría en unos dos millones y medio de reales de vellón de superávit. En 1791, las extracciones se elevan a cerca del millón y medio de reales, y las introducciones compilan aproximadamente dos millones. Pero véase que los capitales repatriados significan 3,8 millones: de nuevo, el resultado sería satisfactorio para Mallorca en

24 C. Mancra (1988a: 274-276). 
unos 3,3 millones. Tal vez sea casual que los materiales disponibles manifiesten balances positivos para la isla, y cabe presuponer que, en otros años, la realidad no debió ser tan favorable. Pero lo más destacable es que estas remesas de capitales, fruto de negociaciones en otras ciudades, constituyeron una fórmula efectiva para compensar la inestabilidad de la balanza comercial. Por otra parte, nótese que las principales sumas proceden de los mercados catalán y regional, coincidiendo con la periodización del tráfico oleícola que ya he establecido en otro lugar ${ }^{25}$. Ello confirma el peso progresivo del ámbito ibérico sobre el resto de las áreas comerciales estimuladas por los cargadores insulares.

De lo expuesto se derivan dos cuestiones principales. En primer lugar, el déficit de la balanza comercial no es perpetuo, si bien los desequilibrios que se producen pueden ser muy importantes, sobre todo en los años en los que las compras de cereales son copiosas. Ahora bien, esto no es sinónimo de un endeudamiento imparable de la economía mallorquina. Urge recordar, en este sentido, que la influencia de la aristocracia ilustrada se ha dejado sentir demasiado en algunas interpretaciones historiográficas, sustentadas en la lectura irreflexiva de los textos de los Amigos del País, quienes, con una hábil estrategia tendente a desacreditar a los comerciantes, describen un panorama mercantil harto desolador para la isla. Esa visión no acierta a explicar, sin embargo, cómo es posible que una balanza comercial siempre deficitaria - generando, se nos dice, una economía débil - pueda proporcionar los flujos monetarios que se traducen en capítulo ineludible para adquirir los grandes cargamentos cerealícolas, perentorios en el mercado urbano mallorquín. En segundo término, se entiende la posibilidad de adquirir los alimentos básicos que faltan en la isla si se adopta una orientación más amplia de la estrategia comercial de los mallorquines. La fuerte competitividad de los mercados impone una cuidada política de reducción de los costes de transacción, lo cual significa disponer de una información lo más puntual posible -sobre precios, necesidades de consumo, fletes, seguros-que, a su vez, permita conocer mejor las fluctuaciones de las diferentes demandas. E. J. Nell ${ }^{26}$ nos ha enseñado que de esa información depende, en suma, el beneficio. Este panorama promueve el trabajo de los comerciantes en los centros principales, medite. rráneos y atlánticos, mediante la instalación de hombres de su entera confianza, que se convierten en sus verdaderos enlaces con aquellas plazas de interés prioritario. Es decir, se impone considerar que el propio mercado no es la única área contemplada en el volumen de negocios del cargador, toda vez que esa "diáspora comercial" inserta a los mercaderes en demandas

25 C. Manera (1988a: 32-126).

26 E. J. Nell (1984: especialmente 67-68 y 78-86). 
más diversificadas y en núcleos de una oferta también mayor. Los capitales obtenidos con las operaciones derivadas de tal planteamiento económico representan, una vez remitidos a Mallorca, partidas compensatorias que ayudan a equilibrar la balanza de pagos.

En definitiva, la infraestructura formada por el capital comercial insular en los principales enclaves del mercado mundial constituye uno de los factores que permite comprender los mecanismos reguladores de una economía que, a causa del déficit de la balanza comercial, parecía caracterizada por su endeblez y escasa capacidad de respuesta.

\section{A MODO DE CONCLUSION. EL CAMBIO ECONOMICO: CUESTION ECONOMICA, CUESTION SOCIAL}

Las páginas anteriores han apuntado las principales características del cambio económico que conoce Mallorca durante el Setecientos. Ese cambio tiene unos protagonistas sociales que no son, únicamente, los colectivos privilegiados de la sociedad insular; al mismo tiempo, se explica por las relaciones de producción que va forjando la estructura económica. En tal sentido, es apremiante incorporar unas consideraciones que aporten nuevos elementos de discusión sobre la estructura de clases mallorquina. Interesa subrayar especialmente cuatro puntos:

1. Los grupos sociales dominantes - aristocracia, grandes comerciantes- utilizan la escasez de subsistencias como mecanismo de control del orden social interno, e instrumento para alcanzar reducciones en las cargas fiscales. El déficit triguero, tal y como se presenta en los textos de los administradores isleños, no siempre se corresponde con la realidad. Se persigue la obtención del máximo beneficio por las altas cotizaciones del trigo en el mercado, y la condonación de parte de las tasas aduaneras con la finalidad de facilitar las importaciones. Sin embargo, la penuria alimenticia se convierte en un fenómeno cotidiano para la población: la subproducción cerealícola es estructural, y sus consecuencias se agudizan durante las crisis de subsistencias. Ello implica la adopción de medidas constantes de aprovisionamiento, y el interés por conocer el estado productivo de la isla.

2. La dependencia exterior frumentaria no comporta, necesariamente, la vertiente dramática que con asiduidad se ha presentado, partiendo casi siempre de una lectura acrítica de los textos coetáneos. Los flujos comerciales que atraviesan el Mediterráneo, y los que se generan desde la bahía mallorquina, garantizan suficientemente las urgencias de grano: las cifras son, en tal sentido, bien elocuentes. Esto no evita la reiteración de quejas y 
protestas por parte de las autoridades locales, con los objetivos de carácter político-económico ya expresados. Y, obviamente, no elude el problema de la escasez y del hambre, consecuencia más de la especulación que de la falta real de trigo en los pósitos particulares. La situación "semiperiférica" de Mallorca - utilizando el término wallersteniano- es, pues, un factor que favorece el avituallamiento de grano, tal y como sucede en otros puntos del litoral peninsular, al disponer de positivas rentas de localización. Además, cabe considerar que en el exterior el precio del trigo es inferior al formado en el mercado de Palma. Es decir, el cereal es más caro en el primordial núcleo urbano mallorquín que fuera de la isla, bien por los costes de producción - cuestión que no es fácil de constatar por el momento-, bien por las prácticas agiotistas, de manera que ese margen constituye, como es lógico, uno de los ejes cruciales de las transacciones de los comerciantes.

3. Se articulan respuestas concretas a las fluctuaciones de los valores cerealícolas, debido a las bruscas oscilaciones de las cosechas: en ese contexto hay que entender, por ejemplo, el vigoroso crecimiento de las legum. bres, cada vez más relevantes en la dieta de las clases populares; o el avance de la viticultura, relacionado con las demandas interna y externa. En ambos casos, los grupos sociales menos favorecidos tienen un protagonismo claro - como detentadores de excedentes-, hecho poco o nada perceptible en los casos de los capítulos tradicionales de la economía isleña, el aceite y el trigo, controlados por aristócratas y, sobre todo, comerciantes. Es éste un aspecto que conviene resaltar, toda vez que sugiere mecanismos claros de resistencia económica por parte de los más desposeídos. Ahora bien, no es fácil discernir por el momento - resta mucha investigación por delantesi esa inserción comercial, por parte de tales colectivos, obedece a una negociación "voluntaria", basada en respuestas positivas dentro de un "modelo de especialización", o, por el contrario, nos enfrentamos a esa "comercialización forzada" que A. Bhaduri-recogiendo el concepto de W. Kula - ha puntualizado como una integración en el mercado mucho más compulsiva e involuntaria, extensible tanto al mercado de bienes como a los de trabajo, tierra y crédito ${ }^{27}$.

4. Por consiguiente, el campesinado mallorquín no permanece impasible a las crisis de subsistencias; es decir, la sobreexplotación que padece ha de generar reacciones precisas para limitar la sostracción señorial. El campesino, como el artesano más humilde, no es un agente paciente, casi inerme, que sufre en un silencio total, en una inactividad absoluta y secular, la acción depredadora de la clase dominante. Tal vez una idea harto matizable, frecuente por otra parte entre los historiadores, sea pensar que el des-

27 A. Bhaduri (1987: 35-65). 
contento siempre debe traducirse en movimiento claramente articulado, en conflicto abierto. Pero la respuesta que ofrece la clase dominada no es estrictamente sociopolítica, no se concentra en revueltas populares y movilizaciones más o menos violentas. Campesinos y artesanos parecen "racionalizar" la explotación; es decir, asimilan culturalmente su situación de derrota, a la que difícilmente pueden plantear mecanismos de oposición organi$\mathrm{zada}^{28}$. Las clases populares disponen de otras fórmulas de antagonismo, procesos más vinculados a factores socioeconómicos que no a los estrictamente políticos. La lucha de esos grupos constituye una larga cadena de resistencias: la intervención en la compleja red del contrabando, la inserción en infraestructuras manufactureras, el fraude fiscal, los cultivos alternativos, la participación en la fabricación de licores, representan, entre otros que ahora desconocemos, vertientes concretas que lo ejemplifican.

Estamos, pues, ante elementos que pueden rivalizar con segmentos de la clase dominante, en el seno de una estructura económica dinámica, no fosilizada, que se va transformando en función de los intereses de los dominadores, pero también de las reacciones de los dominados. Se apuntan, por tanto, algunas de las manifestaciones que permiten explicar el eje central que sustenta la estrategia de los desposeídos, y que puede especificarse con una palabra: resistir. Para, en definitiva, crecer.

2x Véanse el ya clásico trabajo de E. P. Thompsom (1979) y el capítulo Il de la primera parte del excelente libro de G. Ste. Croix (1988: 46-136). 


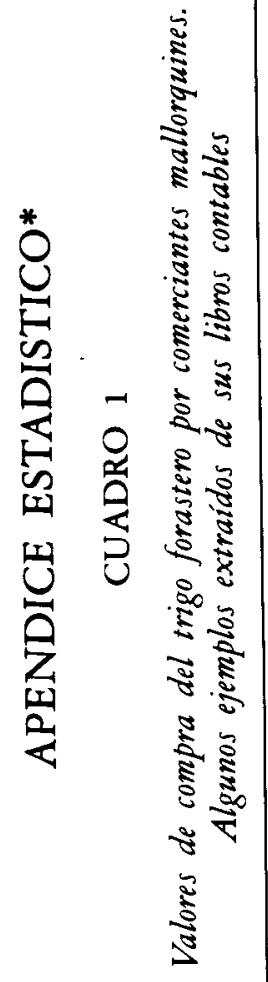

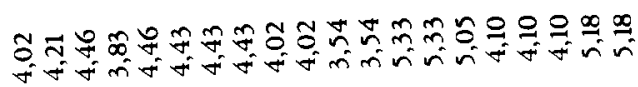

ะ

2.

:

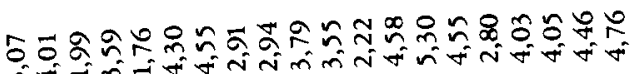

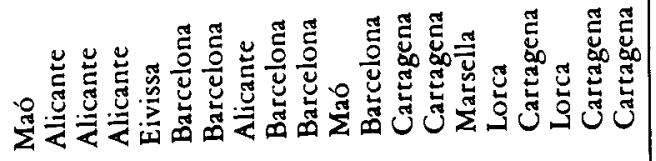

$\frac{0}{3}$

䒿

号

$\bar{\xi}$

$y$

疍 in

$\frac{5}{2}$

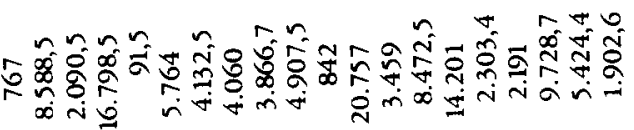




\section{CUADRO 2}

Matrices de correlación entre las producciones de cereales y legumbres

\begin{tabular}{|c|c|c|c|c|c|c|}
\hline & Trigo & Cebada & Avena & Legumbres & $\bar{X}$ & $\begin{array}{l}\text { Desvia- } \\
\text { ción st. }\end{array}$ \\
\hline \multicolumn{7}{|l|}{$1717 \cdot 1752$} \\
\hline Trigo .................. & 1,00 & & & & 336.130 & 95.422 \\
\hline 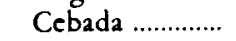 & 0,73 & 1,00 & & & 157.206 & 48.112 \\
\hline 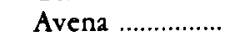 & 0,73 & 0,78 & 1,00 & & 99.598 & 40.484 \\
\hline Legumbres ...... & 0,65 & 0,39 & 0,50 & 1,00 & 55.826 & 20.807 \\
\hline \multicolumn{7}{|l|}{$1753-1785$} \\
\hline Trigo ................... & 1,00 & & & & 326.104 & 53.279 \\
\hline Cebada ................. & 0,69 & 1,00 & & & 134.446 & 24.014 \\
\hline 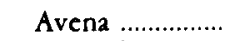 & 0,68 & 0,63 & 1,00 & & 92.571 & 20.041 \\
\hline Legumbres ...... & 0,71 & 0,57 & 0,66 & 1,00 & 66.993 & 15.342 \\
\hline \multicolumn{7}{|l|}{$1786-1819$} \\
\hline Trigo .................... & 1,00 & & & & 308.642 & 71.332 \\
\hline Cebada .................. & 0,46 & 1,00 & & & 163.529 & 30.179 \\
\hline Avena ...................... & 0,66 & 0,70 & 1,00 & & 103.445 & 24.685 \\
\hline Legumbres ....... & 0,56 & 0,39 & 0,68 & 1,00 & 82.498 & 26.777 \\
\hline
\end{tabular}

Fuente: Elaboración personal sobre los datos de J. Juan (1978). 


\section{CUADRO 3}

Producción (P.), precios (Pr.) de Palma e importaciones (I.) de cereales (En cuarteras)

\begin{tabular}{|c|c|c|c|c|c|c|}
\hline & $\begin{array}{c}P \\
\text { trigo }\end{array}$ & $\begin{array}{c}\text { I. } \\
\text { trigo }\end{array}$ & $\begin{array}{c}\text { Pr. } \\
\text { trigo }\end{array}$ & $\begin{array}{c}P \\
\text { cebada } \\
\end{array}$ & $\begin{array}{c}I . \\
\text { cebada }\end{array}$ & $\begin{array}{c}\text { Pr. } \\
\text { cebada }\end{array}$ \\
\hline 1779 & 250.950 & 19.378 & 106,67 & 118.713 & 1.535 & 45,08 \\
\hline 1780 & 265.409 & 65.635 & 101 & 145.707 & 1.328 & 44,92 \\
\hline $1781 \ldots \ldots \ldots \ldots \ldots \ldots \ldots$ & 363.107 & 16.645 & 86 & 179.005 & 4.500 & 39,17 \\
\hline 1782 & 328.347 & 23.656 & 82 & 140.808 & - & 37,75 \\
\hline 1783 & 374.773 & 3.716 & 76,33 & 180.292 & 1.062 & 34,50 \\
\hline 1784 & 207.524 & 19.233 & 92,50 & 102.316 & 2.175 & 44,75 \\
\hline $1785 \ldots \ldots$. & 418.940 & 72.631 & 103,50 & 156.419 & 2.678 & 49,33 \\
\hline 1786 & 356.502 & 16.022 & 85,67 & 114.660 & 900 & 44,08 \\
\hline $1787 \ldots \ldots \ldots \ldots \ldots \ldots$ & 397.773 & 790 & 81,50 & 190.923 & - & 38,08 \\
\hline 1788 & 193.135 & 81.000 & 95,33 & 125.817 & 4.955 & 44,50 \\
\hline 1789 & 300.354 & 75.344 & 113,92 & 192.123 & 3.200 & 55,08 \\
\hline 1790 & 438.167 & 31.448 & 102,67 & 189.999 & 8.997 & 46,67 \\
\hline 1791 & 335.272 & 22.307 & 90,17 & 145.657 & 6.275 & 43,67 \\
\hline 1792 & 274.254 & 67.066 & 103,08 & 128.737 & 10.122 & 49,17 \\
\hline $1793 \ldots \ldots \ldots \ldots \ldots \ldots$ & 418.783 & 21.734 & 122,83 & 225.908 & 3.576 & 58,92 \\
\hline 1794 & 270.465 & 25.757 & 121,25 & 138.908 & 8.174 & 55,33 \\
\hline 1795 & 308.949 & 65.911 & 134,83 & 151.318 & 10.340 & 58,67 \\
\hline 1796 & 317.728 & 72.380 & 134,17 & 177.351 & 1.174 & 58,25 \\
\hline 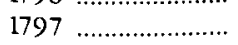 & 340.727 & 40.901 & 128,75 & 179.487 & 1.200 & 58,75 \\
\hline $1798 \ldots \ldots \ldots \ldots \ldots \ldots$ & 296.333 & 48.712 & 108,17 & 168.733 & 241 & 57,17 \\
\hline 1799 & 334.170 & 52.512 & 167,92 & 171.603 & 4.203 & 75,75 \\
\hline 1800 & 329.776 & 106.628 & 154 & 152.606 & 21.309 & 74,42 \\
\hline 1801 & 299.239 & 36.107 & 122,25 & 178.950 & 3.528 & 61,17 \\
\hline 1802 & 379.461 & 35.082 & 132,33 & 173.135 & 1.185 & 60,08 \\
\hline $1803 \ldots \ldots \ldots \ldots \ldots \ldots$ & 274.629 & 52.583 & 136,83 & 144.887 & 17.773 & 66,92 \\
\hline .......................... & 226.053 & 420.273 & 150,50 & 205.130 & 11.210 & 74,42 \\
\hline 1805 & 308.370 & 256.452 & 172,67 & 171.313 & 5.048 & 75,25 \\
\hline 1806 & 409.164 & 213.600 & 127,58 & 165.460 & 11.488 & 59,50 \\
\hline 1807 & 336.640 & 41.273 & 124,58 & 163.215 & 513 & 59,25 \\
\hline 1808 & 370.108 & 4.687 & 131,42 & 205.366 & - & 65,25 \\
\hline
\end{tabular}

Fuentes: Para la producción, J. Juan (1978). Para las importaciones, elaboración personal sobre los datos del Semanario Económico y el Arxiu Municipal de Palma, legajo 821. Los precios, calculados por medias anuales y en sous por cuartera, me han sido proporcionados por el amigo B. Orell. 


\section{CUADRO 4}

Importaciones de arroz por el puerto de Palma

\begin{tabular}{|c|c|c|c|}
\hline & Años & & Cantidades - \\
\hline 1779 & 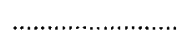 & $3.922, \quad 100$ & c. \\
\hline 1780 & …....................... & 5.775 & \\
\hline 1781 & (n........................ & 3.966 & 0 c., 450 qu. \\
\hline 1782 & ....................... & 1.717 & \\
\hline 1783 & , & 4.253 & \\
\hline 1784 & (........................... & 340 & c. \\
\hline 1785 & . & $2.343,3.589$ & c. \\
\hline 1786 & 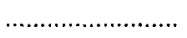 & 5.722 & $1.795 \mathrm{ca}$. \\
\hline 1787 & . & $7.327,1.618$ & c. \\
\hline 1788 & … & $2.609,2.971$ & c., $\quad 450$ q., 1.040 qu. \\
\hline 1789 & . & $4.202,2.893$ & c. \\
\hline 1790 & (...................... & $1.529,1.656$ & c. \\
\hline 1791 & 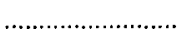 & $37.295,1.085$ & 970 qu. \\
\hline 1792 & (...................... & $2.775,3.197$ & c., 1.400 qu. \\
\hline 1793 & ............................ & $4.069,705$ & c. \\
\hline 1794 & (............................. & 382 & \\
\hline 1795 & (........................... & $2.524,934$ & c. \\
\hline 1796 & ............................ & $768, \quad 170$ & $65 \mathrm{qu}$. \\
\hline 1797 & (........................ & 220 & 100 qu. \\
\hline 1798 & 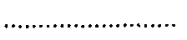 & $7.983,505$ & c. \\
\hline 1799 & ……............... & 12.186, & 60 qu. \\
\hline 1800 & …........................ & 18.350 & $c$. \\
\hline 1801 & (.......................... & 9.185 & \\
\hline 1802 & ............................ & 7.740 & 20 qu., 10 b., 25 t. \\
\hline 1803 & , & 10.340 & 300 qu. \\
\hline 1804 & 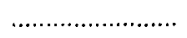 & $7.460, \quad 845$ & $30 \mathrm{~b}$ \\
\hline 1805 & …………............ & $7.862, \quad 668$ & c. \\
\hline 1806 & (...................... & $6.972,1.872$ & c. \\
\hline 1807 & . & $2.645,4.051$ & c. \\
\hline 1808 & 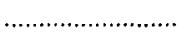 & 234 & c. \\
\hline
\end{tabular}

Las cifras sin referencia son sacos.

Referencias: $\quad c .=$ carga; $q u=$ quintal; $\quad c a .=c a j a ; \quad b .=b a r r i l e s$; $\mathrm{t} .=$ toneladas.

Fuente: Elaboración personal sobre los datos del Semanario Económico. 


\section{CUADRO 5}

Cantidades procedentes de los diezmos, destinadas a la provisión de subsistencias, 1800

\begin{tabular}{|c|c|c|c|c|}
\hline Villas & Producto & Cuarteras & $\begin{array}{c}\text { Precio } \\
\text { por cuartera }\end{array}$ & $\begin{array}{l}\text { Valor total } \\
\text { (lliures) }\end{array}$ \\
\hline 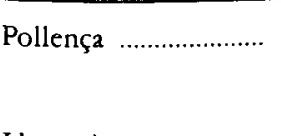 & $\begin{array}{l}\text { Trigo } \\
\text { Cebada } \\
\text { Avena }\end{array}$ & $\begin{array}{r}90 \\
8 \\
10\end{array}$ & $\begin{array}{l}6,90 \\
3,30 \\
2,25\end{array}$ & $\begin{array}{r}598,80 \\
26,75 \\
19,75\end{array}$ \\
\hline Llucmajor ........................ & $\begin{array}{l}\text { Cebada } \\
\text { Avena } \\
\text { Habas }\end{array}$ & $\begin{array}{r}220 \\
100 \\
40\end{array}$ & $\begin{array}{l}3,30 \\
2,25 \\
5,40\end{array}$ & $\begin{array}{l}691 \\
212,50 \\
206,50\end{array}$ \\
\hline Manacor …….................. & $\begin{array}{l}\text { Trigo** } \\
\text { Cebada } \\
\text { Avena } \\
\text { Habas }\end{array}$ & $\begin{array}{r}204 \\
257 \\
88 \\
50\end{array}$ & $\begin{array}{l}6,60 \\
3,30 \\
2,25 \\
5,40\end{array}$ & $\begin{array}{l}1.275 \\
766,30 \\
172,35 \\
251\end{array}$ \\
\hline Felanitx & $\begin{array}{l}\text { Trigo** } \\
\text { Cebada } \\
\text { Avena } \\
\text { Habas }\end{array}$ & $\begin{array}{r}70 \\
175 \\
100 \\
50\end{array}$ & $\begin{array}{l}6,60 \\
3,30 \\
2,25 \\
5,40\end{array}$ & $\begin{array}{l}439,25 \\
522 \\
192,50 \\
251,85\end{array}$ \\
\hline 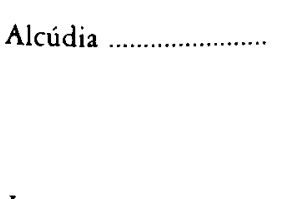 & $\begin{array}{l}\text { Candeal } \\
\text { Trigo** } \\
\text { Cebada } \\
\text { Avena } \\
\text { Habas }\end{array}$ & $\begin{array}{r}15 \\
208 \\
91 \\
58 \\
90\end{array}$ & $\begin{array}{l}8,40 \\
6,60 \\
3,30 \\
2,25 \\
5,40\end{array}$ & $\begin{array}{c}127,95 \\
1.311 \\
272,90 \\
113,90 \\
456,35\end{array}$ \\
\hline Inca & $\begin{array}{l}\text { Trigo } \\
\text { Trigo** } \\
\text { Cebada } \\
\text { Avena } \\
\text { Habas }\end{array}$ & $\begin{array}{r}45 \\
261 \\
166 \\
66 \\
108\end{array}$ & $\begin{array}{l}6,90 \\
6,60 \\
3,30 \\
2,25 \\
5,40\end{array}$ & $\begin{array}{c}303,65 \\
1.659 \\
515,75 \\
137,80 \\
549,50\end{array}$ \\
\hline
\end{tabular}

* Se excluyen los gastos de transporte.

** Trigo "menudo".

Fuente: Elaboración personal sobre los datos del Arxiu del Regne de Mallorca, «Reial Patrimoni», núm. $3614(3614 / 24)$. 


\section{CUADRO 6}

Valores de los diezmos de determinadas producciones (En lliures mallorquinas)

\begin{tabular}{|c|c|c|c|c|c|}
\hline & Años & $\begin{array}{l}\text { Granos y } \\
\text { legumbres* }\end{array}$ & Aceite* & Vino & Hortalizas \\
\hline 1803 & . & 78.482 & 1.130 & 8.800 & 3.638 \\
\hline 1804 & 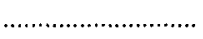 & .67 .238 & 3.757 & 8.506 & 3.667 \\
\hline 1805 & 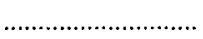 & 65.836 & 7.192 & 5.282 & 3.943 \\
\hline 1806 & 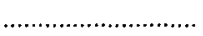 & 68.759 & 7.511 & 6.718 & 4.680 \\
\hline \multirow[t]{2}{*}{1807} & 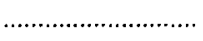 & 71.834 & 8.069 & 7.599 & 4.385 \\
\hline & & 352.149 & 27.659 & 34.205 & 20.313 \\
\hline
\end{tabular}

* Se han descontado los gastos de administración. En los casos de las hortalizas y del vino no se ocasionan gastos a la Real Hacienda, dado que se venden en pública subasta, rematada al mejor postor, encargándose de recoger él mismo el diezmo.

Fuente: Elaboración personal sobre los datos del Arxiu del Regne de Mallorca, "Reial Patrimoni», núm. 1285 (1285/7). 


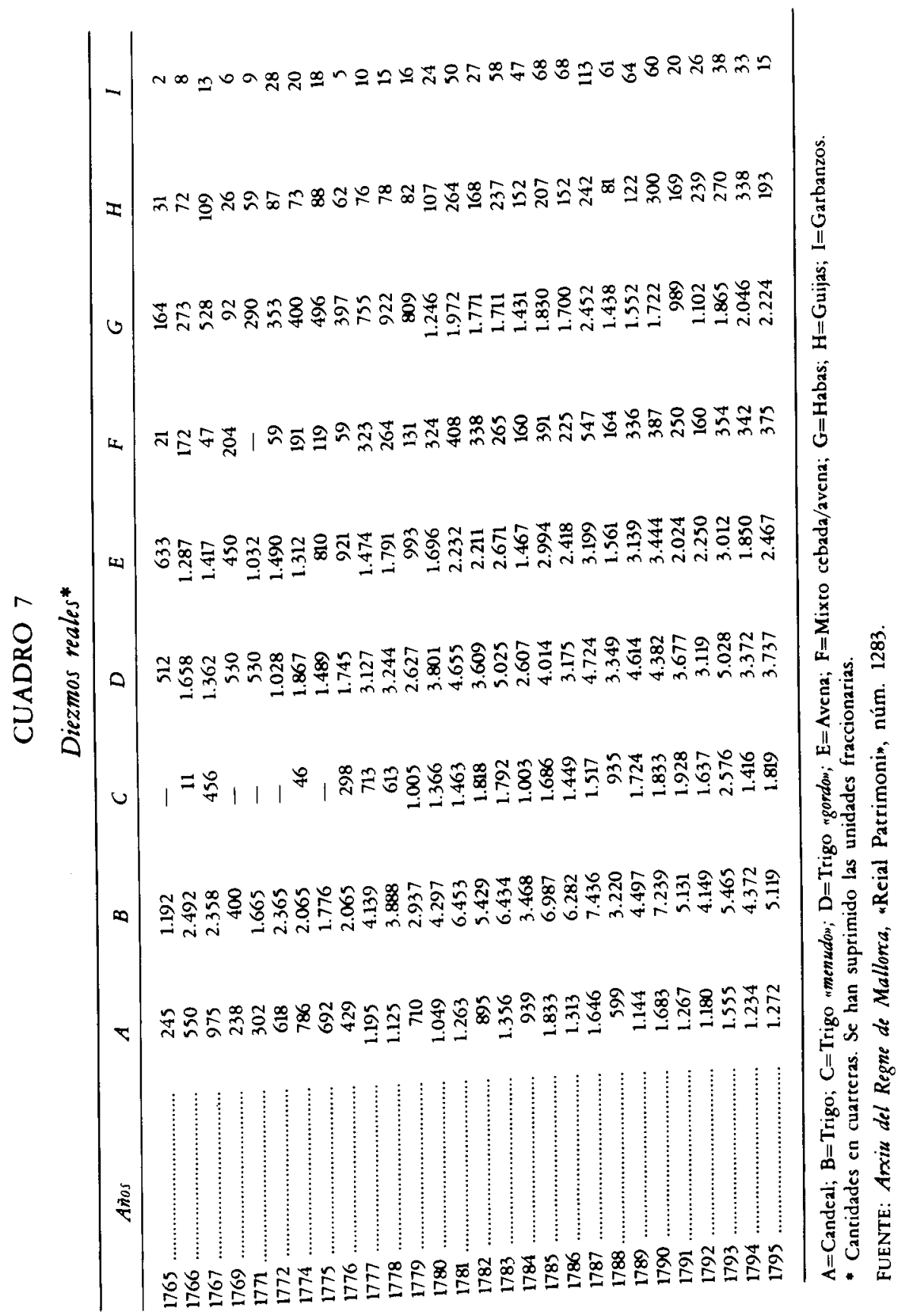




\section{CUADRO 8}

Valor del comercio por el puerto de Palma

(En reales de vellón)

\begin{tabular}{|c|c|c|c|}
\hline Años & Importaciones* & Exportaciones** & Total \\
\hline $1742 \ldots \ldots$ & 1.781 .613 & 2.044 .867 & 3.826 .480 \\
\hline 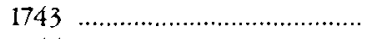 & 2.122 .387 & 3.934 .793 & 6.057 .180 \\
\hline 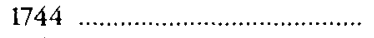 & 1.399 .373 & 2.509 .113 & 3.908 .486 \\
\hline 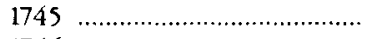 & 1.205 .100 & 3.586 .900 & 4.792 .000 \\
\hline 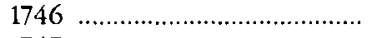 & 1.669 .793 & 2.670 .293 & 4.340 .086 \\
\hline 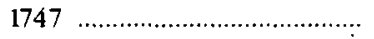 & 1.310 .853 & 2.402 .120 & 3.712 .973 \\
\hline 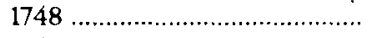 & 1.385 .787 & 2.371 .446 & 3.757 .233 \\
\hline 1749 & 1.799 .307 & 2.563 .687 & 4.362 .994 \\
\hline 1750 & 870.280 & 1.913 .087 & 2.783 .367 \\
\hline 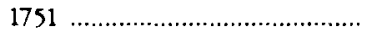 & 1.406 .053 & 4.176 .533 & 5.582 .586 \\
\hline 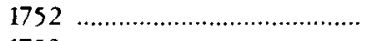 & 1.735 .847 & 2.909 .913 & 4.645 .760 \\
\hline 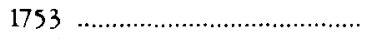 & 1.520 .827 & 3.381 .826 & 4.902 .653 \\
\hline 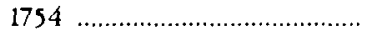 & 2.767 .067 & 5.394 .367 & 8.161 .434 \\
\hline 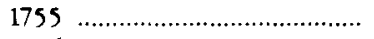 & 1.448 .653 & 2.828.527 & 4.277 .180 \\
\hline 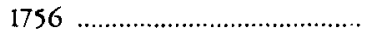 & 2.069 .787 & 5.223 .426 & 7.293 .213 \\
\hline $1757 \ldots \ldots \ldots \ldots \ldots \ldots \ldots$ & 2.716 .673 & 3.300 .260 & 6.016 .933 \\
\hline 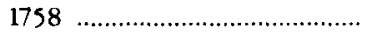 & 1.840 .773 & 3.403 .200 & 5.243 .973 \\
\hline 1759 & 1.489 .060 & 2.607 .527 & 4.096 .587 \\
\hline 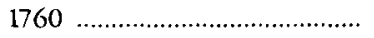 & 1.437 .200 & 1.843 .013 & 3.280 .213 \\
\hline 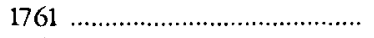 & 1.559 .860 & 981.780 & 2.541 .640 \\
\hline 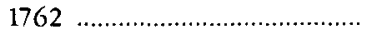 & 2.052 .807 & 4.401 .866 & 6.454 .673 \\
\hline 1763 & 2.172 .667 & 4.081 .293 & 6.253 .960 \\
\hline 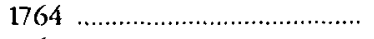 & 2.430 .673 & 1.340 .073 & 3.770 .746 \\
\hline 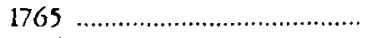 & 1.751 .953 & 2.554 .060 & 4.306 .013 \\
\hline 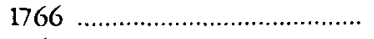 & 2.608 .853 & 3.712 .567 & 6.321 .420 \\
\hline 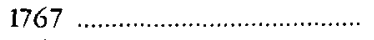 & 2.409 .313 & 4.125 .920 & 6.535 .233 \\
\hline 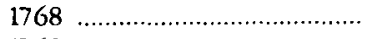 & 1.790 .993 & 2.249 .407 & 4.040 .400 \\
\hline 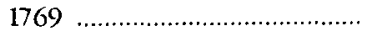 & 1.149 .040 & $1,803.960$ & 2.953 .000 \\
\hline 1770 & 2.213 .606 & 2.761 .413 & 4.975 .019 \\
\hline 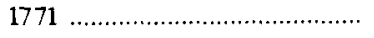 & 1.513 .740 & 2.314 .107 & 3.827 .847 \\
\hline 1772 & 2.041 .547 & 3.003 .413 & 5.044 .960 \\
\hline 1773 & 1.808 .860 & 706.553 & 2.515 .413 \\
\hline 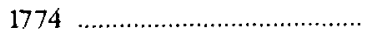 & 1.549 .253 & 3.653 .060 & 5.202 .313 \\
\hline 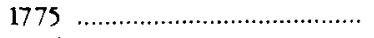 & 1.555 .520 & 1.872 .820 & 3.428 .340 \\
\hline 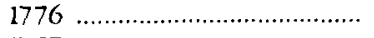 & 1.401 .707 & 5.163 .400 & 6.565 .107 \\
\hline 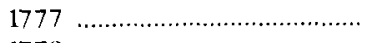 & 1.206 .867 & 3.126 .626 & 4.333 .493 \\
\hline 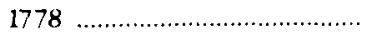 & 967.100 & 3.208 .327 & 4.175 .427 \\
\hline 1779 & 784.067 & 2.213 .566 & 2.997 .633 \\
\hline 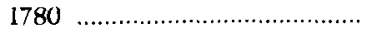 & 1.159 .353 & 1.022 .620 & 2.181 .973 \\
\hline
\end{tabular}

* Menos los cereales panificables.

* Valores de todas las exportaciones.

FUeNTE: Elaboración personal en base a los impuestos que gravan las entradas y salidas principalmente, el del 15 por 100-, localizados en el Archivo General de Simancas. "Dirección General de Rentas", 1." remesa, legajos 2506 a 2565. 


\section{CUADRO 9}

Valor de los cereales importados por el puerto de Palma (A precios corrientes del mercado de Palma)

\begin{tabular}{|c|c|}
\hline$A$ ños & $\begin{array}{c}\text { Cantidad en reales } \\
\text { de vellon }\end{array}$ \\
\hline (1) & 1.065 .927 \\
\hline 1782 & 1.286 .082 \\
\hline 1783 & 212.345 \\
\hline 1784 & 1.244 .041 \\
\hline 1785 & 5.071 .561 \\
\hline 1786 & 936.339 \\
\hline 1787 & 42.687 \\
\hline 1788 & 5.265 .696 \\
\hline 1789 & 5.809 .009 \\
\hline 1790 & 2.419 .059 \\
\hline 1791 & 1.515 .254 \\
\hline 1792 & 4.913 .401 \\
\hline 1793 & $1,909.628$ \\
\hline 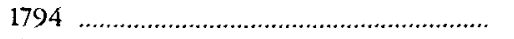 & 2.370 .426 \\
\hline $1795 \ldots \ldots \ldots \ldots$ & 6.294 .142 \\
\hline $1796 \ldots \ldots \ldots \ldots$ & 6.483 .881 \\
\hline 1797 & 3.538 .101 \\
\hline 1798 & 3.502 .598 \\
\hline 1799 & 6.057 .295 \\
\hline 1800 & 11.938 .328 \\
\hline 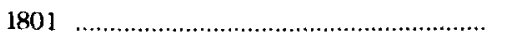 & 3.069 .615 \\
\hline 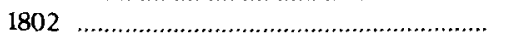 & 3.125 .114 \\
\hline $1803 \ldots \ldots \ldots \ldots \ldots \ldots \ldots$ & 5.558 .791 \\
\hline 1804 & 42.488 .576 \\
\hline 1805 & 29.610 .527 \\
\hline 1806 & 18.520 .655 \\
\hline 1807 & 3.429 .159 \\
\hline 1808 & 408.385 \\
\hline
\end{tabular}

Fuente: Véase el cuadro 3. 


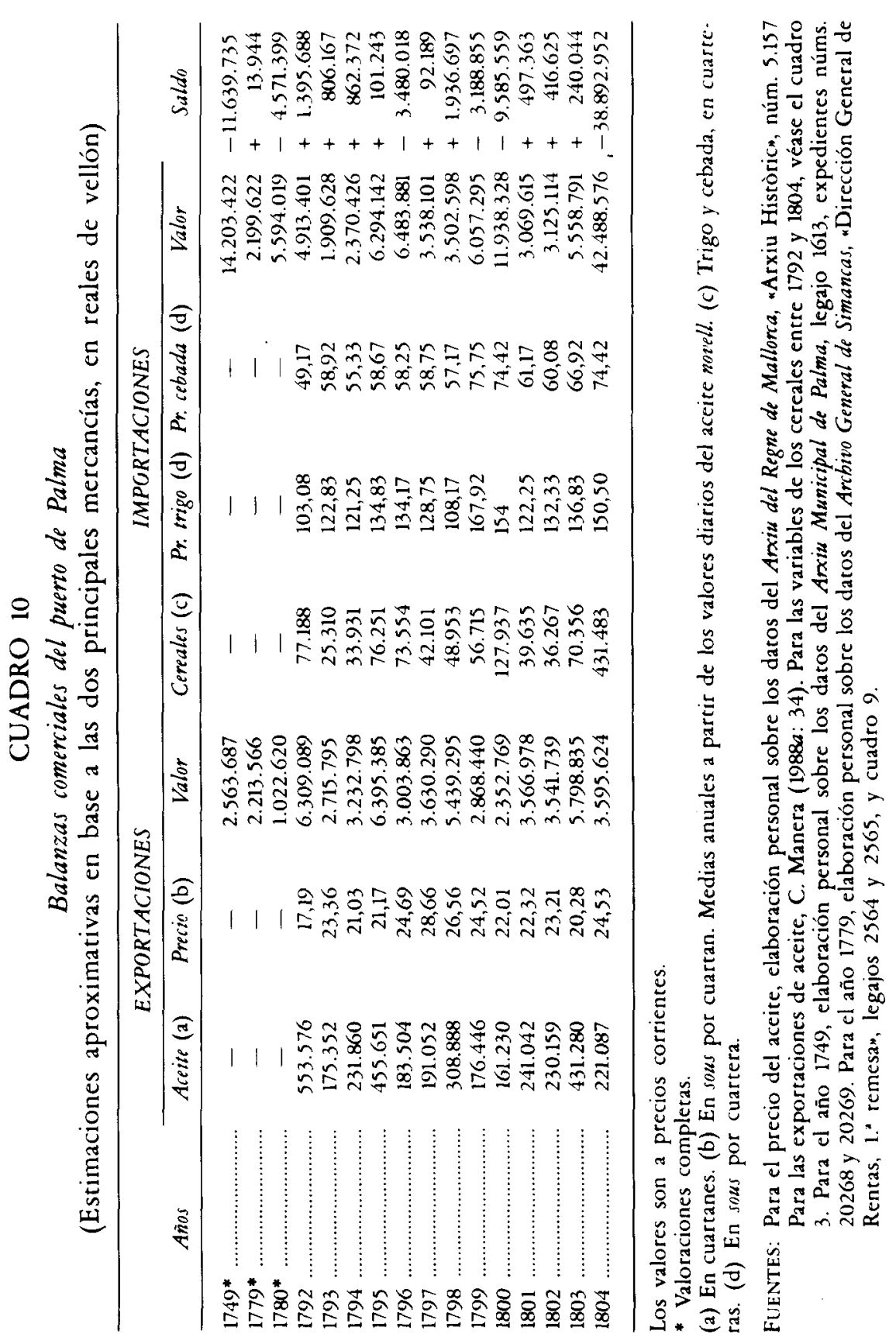




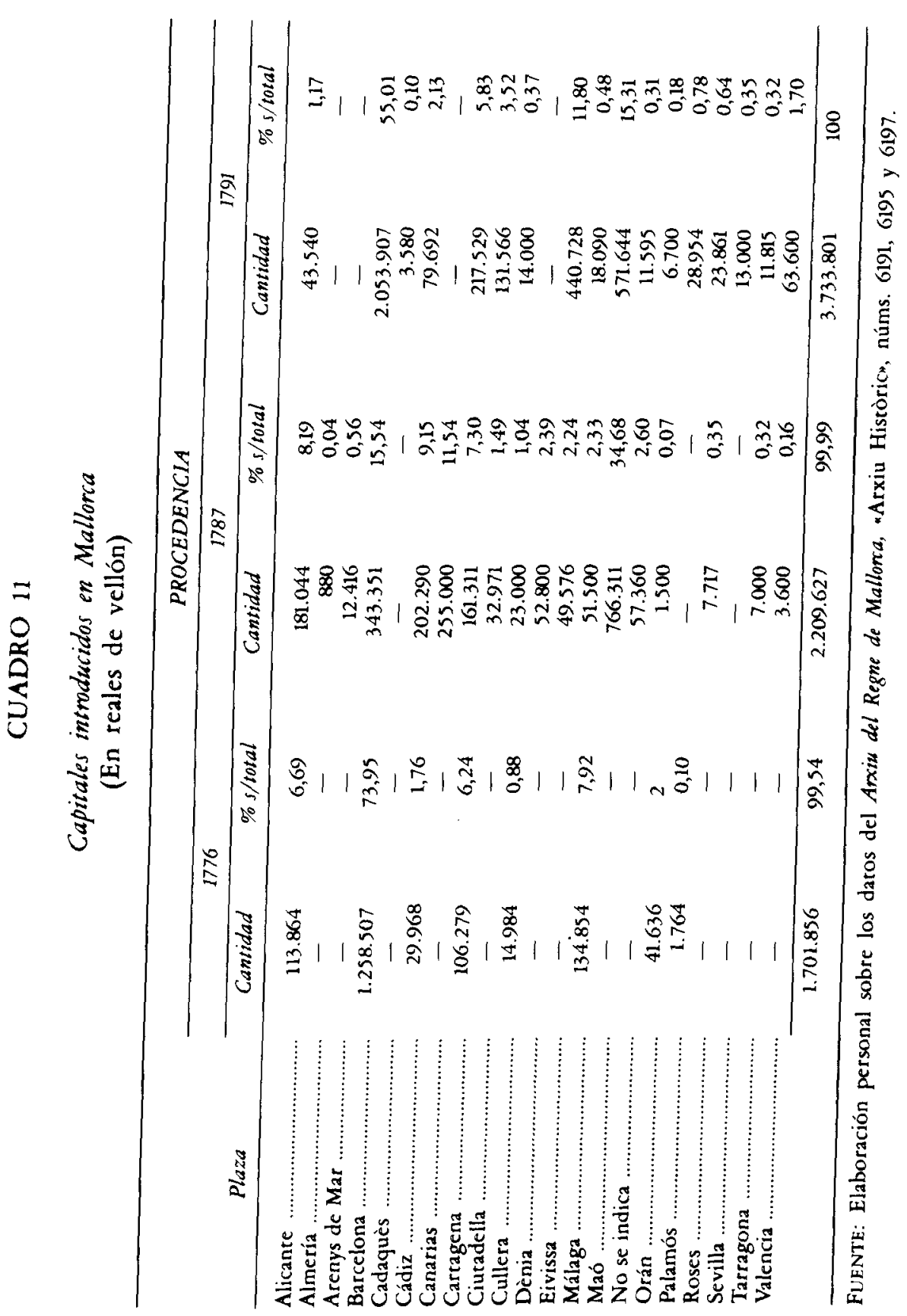




\section{BIBLIOGRAFIA CITADA}

Andújar, M. M.; Molina, O., y Gil, F. (1987): Tablas de composición de alimentos (Madrid). Bejarano, E. (1989): Los gremios y la corporación de los cortantes de Palma en el siglo XVIII. Memotia de Doctorado (inédita).

Bhaduru, A. (1987): La estructura económica de la agriculturáa atrasada (México).

Bibiloni, A. (1988): "Comerç de contraban a Mallorca: 1750-1812. El cas del tabac", Estudis d'Història Economica, 1, pp. 65-97.

Davíu, G. (1983): "La producció d'oli a Mallorca, segle xviII. Aproximació en base a la documentació fiscal*, Actas del Primer Colloqui d'História Agrària (Valencia), pp. 391-410.

DEYÀ, M. (1988): «La industria textil en la Mallorca moderna: producción y formas de comercialización interior", Estudis d'Història Económica, 2, pp. 15-41.

Ferrer, L1. (1987): Pagesos, rabassaires $i$ industrials a la Catalunya central (segles XVIII-XIX). Barcelona.

FindLAY, R. (1975): Comercio y especialización, Madrid.

FONTANA, J. (1986): “La dinámica del mercado interior (algunas reflexiones a propósito del crecimiento de Santander)", en T. Martínez Vara (ed.), Mercado y desarrollo económico en la España contemporánea, Madrid, Siglo XXI, pp. 85-96.

GARCíA CuENCA, T. (1983): "Las rentas generales o de aduanas de 1740 a 1774m, en G. ANES, L. A. Rojo y P. TEDdE (eds.), Historia económica y pensamiento sacial (Madrid), pp. $237-262$.

JUAN, J. (1978): "La evolución de la producción agrícola en Mallorca durante la Edad Moderna. Fuentes y problemas de su estudiom, Moneda y Crédito, núm. 145, pp. 67-99.

- (1980): "La producción de aceite en Mallorca durante la Edad Moderna y su papel en la economía mallorquina*, Bolleti de la Societat Arqueologica Lulliana, núms. 832-833, pp. 519-552.

LOPEZ BONET, J. F. (1986): "Vindicació de les virtuts de l'aiguardent (1642-1643)», Estudis Baleàrics, núm. 20, pp. 37-43.

Manera, C. (1987): Comery $i$ capital mercantil a Mallorca, 1720-1800 (3 vols.), tesis doctoral.

- (1988a): Comerf $i$ capital mercantil a Mallorca, 1720-1800. Palma de Mallorca.

- (1988b): "Comerç, capital mercantil i manufactura textil a Mallorca, 1700-1830", Randa, núm. 23, pp. 39-83.

- (1988c): "Viticultura i mercat. Reflexions sobre la producció i el tràfic de l'aiguardent mallorquí al segle XVIII, Estudis d'Historia Economica, 1, pp. 117-149.

- (1988d): "Manufactura textil y comercio en Mallorca, 1700-1830», REVISTA DE HISTORIA ECONOMICA, 3, pP. 523-555.

Moll, I.; Segura, A., y SuAu, J. (1983): Cronologia de les crisis demografiques a Mallorca. segles XVIII.XIX, Palma de Mallorca.

Moll, I., y SuAU, J. (1985): "Memoria explicativa del estado de la isla de Mallorca en el siglo XVIIIn, en R. FERNÁndeZ (ed.), España en el siglo XVIII. Homenaje a Pierre Vilar. Barcelona, Crítica, pp. 249-288.

Nell, E. J. (1984): Historia y teoría económica, Barcelona, Crítica.

PÉREZ MOREDA, V. (1985): "Consum deficitari, fam i crisis demogràfics a l'Espanya dels segles XVI.XIX", Estudis d'Història Agrària, núm. 5, Pp. 6-24

Quintana, A. (1985): "La dieta alimentícia del xviII: unes reflexions a partir de les sèries de preus de carn i blat", Actas de las III Jomades d'Estudis Historics Locals, pp. 291-303.

Rosselló, J. (1985): "Cómo se alimentaban los PP. Dominicos (s. Xv)", Actas de las III Jomades d'Estudis Historics Locals, pp. 263-275.

Segura, J. (1984): Análisis microeconómico superior. Asignación y precios, Madrid, Alianza.

Segura, A., y SuAu, J. (1984): "Estudi de demografia mallorquina: l'evolució de la población, Randa, núm. 16, pp. 19-61.

Ste. Croix, G. (1988): La lucha de clases en el mundo griego clásico. Barcelona. 
THIRSK, J. (1984): The Rural Economy of England, Londres.

- (1988): "Specialisation and diversification in the rural economy", texto multicopiado presentado a la Ventesima Settimana di Studio del Instituto Internacional de Historia Económica "Francesco Datini" (Prato).

VAQuer, O. (1985): "L'alimentació a la Mallorca de l'Antic Regim", Actas de las III Jomades

d'Estudis Historics Locals, pp. 255-261.
- (1988): Una sociedad del Antiguo Régimen. Felanitx y Mallorca en el siglo XVI, Palma de Mallorca. 